\title{
REVIEW
}

\section{Towards a commercial process for the manufacture of genetically modified $\mathrm{T}$ cells for therapy}

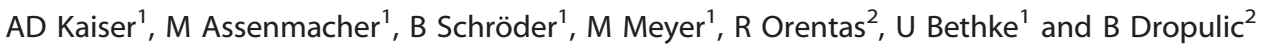

The recent successes of adoptive T-cell immunotherapy for the treatment of hematologic malignancies have highlighted the need for manufacturing processes that are robust and scalable for product commercialization. Here we review some of the more outstanding issues surrounding commercial scale manufacturing of personalized-adoptive T-cell medicinal products. These include closed system operations, improving process robustness and simplifying work flows, reducing labor intensity by implementing process automation, scalability and cost, as well as appropriate testing and tracking of products, all while maintaining strict adherence to Current Good Manufacturing Practices and regulatory guidelines. A decentralized manufacturing model is proposed, where in the future patients' cells could be processed at the point-of-care in the hospital.

Cancer Gene Therapy (2015) 22, 72-78; doi:10.1038/cgt.2014.78; published online 23 January 2015

Redirecting the immune response towards cancer and infectious diseases by genetically engineering T cells for therapy is currently reaching an impressive momentum, with pivotal clinical trials and commercialization of several products on the horizon.

Adoptive cell transfer (ACT) therapy against cancer using T-cell receptor or chimeric antigen receptor (CAR)-retargeted $T$ cells is emerging as an effective and innovative treatment for cancer. ${ }^{1-4}$ Recently, ACT of anti-CD19 CAR-modified T cells resulted in remarkable responses in patients with acute lymphoid leukemia. ${ }^{5,6}$ This success has boosted the field and attracted the attention of the wider scientific and medical community and the public. However, although gene-modified $T$ cells for cancer therapy represents an opportunity for the pharmaceutical industry, cellbased drugs are somewhat different in their development, properties and regulatory pathways than conventional off-theshelf medicines.

The clinical manufacture of gene-modified T cells is currently a complex process that generally starts with obtaining the patient's peripheral blood mononuclear cells (PBMC). Current protocols feature a leukapheresis step, trading off an initially more cumbersome process (as opposed to a smaller volume blood draw) for an increased cell yield. ${ }^{7}$ PBMC are often enriched for $T$ cells and activated prior to gene modification with viral or nonviral vectors. The modified T cells are then expanded in order to reach the cell numbers required for treatment, after which the cells are finally formulated and/or cryopreserved prior to reinfusion (Figure 1). The cell product must be subjected to a number of quality control assays and has to meet all release criteria and Good Manufacturing Practices (GMP) guidelines.

Thus far, ACT using gene-modified $T$ cells has mainly been carried out by investigators who have developed their manufacturing process for small scale clinical trials by using the devices and infrastructure at hand. Anyone who has embarked on the task of manufacturing patient-specific advanced therapeutic medicinal products (ATMP) for clinical use will admittedly agree that it is quite an undertaking. Such individualized therapies are complex: the cell manufacturing process is labor intensive, as it comprises many (open) handling steps (e.g., density gradient cell processing, gene modification, washing, feeding and so on) that require interventions from committed skilled operators who have undergone extensive training. The failure rate can be high owing to the high skill and time demands on clean room personnel to make these complex products. Moreover, dedicated infrastructure with clean rooms and all required instruments must be in place, qualified and functional to ensure aseptic and sterile containment. These requirements restrict such clinical manufacturing to a limited number of institutions worldwide. This in turn confines the number of runs and therefore the number of patients that can be served at any given time. Such unfavorable commercial distribution models impede investment and therefore the broad development of these promising therapies for the patients that need them. ${ }^{8}$

\section{NEED FOR OPTIMIZATION OF MANUFACTURING PROCESSES}

Given the growing interest in the field of gene-modified T-cell therapy, efforts to optimize the manufacturing process are necessary and justified to reach wider dissemination of this therapeutic approach. Several investigators and companies are working on improving manufacturing processes, producing GMP grade materials and finding solutions to bring gene-modified $T$ cells to clinical routine. What are the basic requirements for manufacture of a gene-modified cellular therapy product? First, the manufacturing process must result in a safe and clinically effective cell product for the patient. Second, the process must be robustly reproducible, which is a prerequisite to validate it and to ensure quality during the entire product life-cycle.

These requirements, especially with regard to process, can only be partially met in the currently available clinical manufacturing processes of therapeutic cell products. To overcome this limitation several interconnected aspects must be re-considered: (i) robustness of the cell manufacturing process should be improved to

${ }^{1}$ Miltenyi Biotec GmbH, Bergisch Gladbach, Germany and ${ }^{2}$ Lentigen Technology Inc., Gaithersburg, MD, USA. Correspondence: Dr A Kaiser, Miltenyi Biotec GmbH, Friedrich-EbertStrasse 68, 51429 Bergisch Gladbach, Germany or B Dropulic, Lentigen Technology Inc., 910 Clopper Road, Gaithersburg, MD, USA.

E-mail: andrewk@miltenyibiotec.de or boro.dropulic@lentigen.com

Received 22 October 2014; accepted 5 November 2014; published online 23 January 2015 


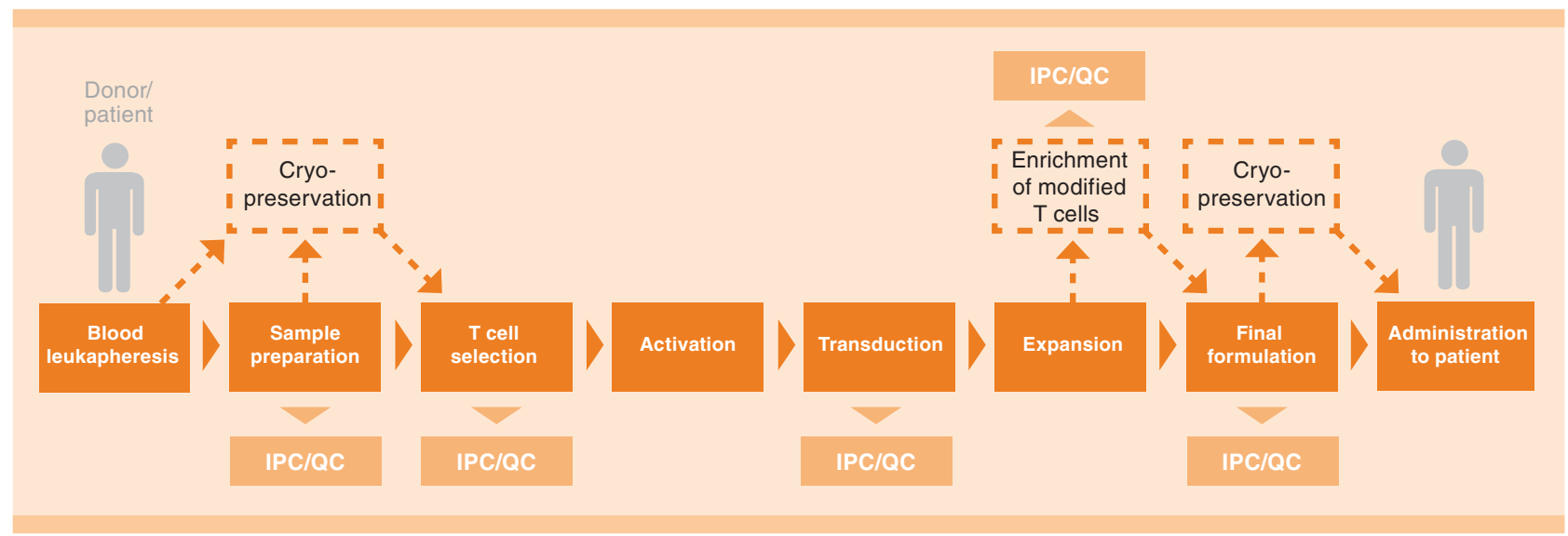

Figure 1. Classical work flow for gene-engineered T-cell production.

abrogate failure risks and enable standardization; especially the integrity and sterility of the process needs to be addressed, because the cultivation of the cells may take several days to weeks; (ii) the process should be simplified as much as possible to enable reproducibility, reduce workload and increase productivity; (iii) the process should be scalable and cost effective to enable product commercialization and availability for patients who need them; and (iv) the process should meet the respective regulatory requirements.

\section{IMPROVING ROBUSTNESS AND RELIABILITY OF THE MANUFACTURING PROCESS}

Use of closed systems

Each manipulation or addition of reagents to the cell preparation (e.g., washes, stimulation, transduction, feeding, sampling) creates a risk for error and for contamination that can lead to a failed production run. A reliable solution consists of implementing closed culture systems, where the cell manufacturing takes place in bags with closed tubing pathways and connections, maintaining a sterile environment. Such a method is described by Tumaini et al. ${ }^{9}$ who implemented a simplified, semi-closed system for the cGMP preparation of anti-CD19 CAR-modified T cells. Several distributors of GMP quality culture bags, tubing accessories and connectors, as well as sterile tubing welders (e.g., Terumo tubing welder, Terumo BCT, Lakewood, CO, USA) make it simpler to convert research protocols to functionally closed manufacturing processes where 'open' process steps are reduced and therefore risks for cross contamination are minimized.

\section{Standardization of input cellular material}

Another advantage of implementing functionally closed systems is the advantage to work in Class 10000 environments (ISO 7) instead of Class 100 (ISO 5) without compromising safe and effective cell production. Class 100 facilities are very expensive to build and operate whereas Class 10000 facilities are less expensive to maintain and more easily implemented (FDA Aseptic Guidance/ ISO 14644).

Patient-derived cells that are used for generation of genemodified $T$ cells can be highly variable as source material. T cells destined to be genetically modified often originate from heavily drug pre-treated patients whose PBMCs may contain abnormal levels of inhibitory factors, inhibitory cells or populations of T cells that poorly respond to stimulation. ${ }^{10-12}$ This clearly challenges our ability to define the reproducibility of the manufacturing process. Separating $T$ cells from these inhibitory elements can greatly improve the outcome of the T-cell culture., ${ }^{9,13,14}$ The use of large magnetic beads coated with anti-CD3 and anti-CD28 (i.e., the CTS Dynabeads CD3/CD28) in combination with a large magnet adapted for bags is an elegant approach that has been successfully implemented in the clinic ${ }^{15}$ as they allow for simultaneous isolation and stimulation of $T$ cells from the PBMC product which enables a more robust process.

Instead of using the entire T-cell population, some investigators have chosen to use specific subsets of $T$ cells for gene modification. For example, antigen-specific $T$ cells already present in memory populations in the patient are optimally primed against viral pathogens. Endogenous antigen-reactive memory $T$ cells against Cytomegalovirus or Epstein-Barr virus have thus been used as a source of T cells for gene- engineering. ${ }^{16}$ Such double-specific $T$ cells present several advantages including the maintenance of CAR specificity on long-lived memory $T$ cells and anti-viral effector activity that prevents viral reactivation following lymphodepletion and ACT..$^{7,18}$ Engagement of their native receptor in vivo by cells infected with these persistent viruses in the host could support T-cell expansion, maintenance and effector function. Initially Epstein-Barr virus-specific T cells generated by conventional in vitro stimulation and expansion protocols have been used. ${ }^{17,18}$ However, these procedures are time-consuming and require extended culture of cells in vitro, which might affect their functionality.

Recently, defined T-cell subsets (i.e., naive, central memory or memory stem cells) have been shown to have important functional advantages and are considered a better source of starting material. ${ }^{19-23}$ Large-scale clinical magnetic enrichment of $T$ cells, as well as naive and central memory subsets can be performed in a closed and sterile system using the CliniMACS plus instrument developed by Miltenyi Biotec, Bergisch Gladbach, Germany. ${ }^{24,25}$ The enriched T cells can then be activated by an alternative clinical reagent TransAct, (Miltenyi Biotec) which is a biodegradable polymeric nanomatrix agonist for CD3 and CD28. ${ }^{24}$ This reagent is compatible with efficient T-cell transduction and is highly suitable for use in aseptic cell manufacturing as it can be sterile filtered.

\section{Qualification and standardization of ancillary reagents}

These complex processes involve many different reagents, for example, separation reagents, activation reagents, viral vectors, media, cytokines, different buffers and so on. These reagents need to efficiently and stably work together as an integrated reagent system. All raw materials in such an integrated system have to meet the requirements according to the recommendations of USP 
$<1043>$ on ancillary materials. Notably, the cell culture media that will be used for commercial scale must be serum free to reduce the risk of contamination with TSE/BSE or viruses. Whenever possible, reagents must be chemically defined. Substances from natural sources, for example, especially serum must be excluded owing to their high variability, limited availability and critical risk profiles. $^{26}$

Finally, an essential part of any multi-step manufacturing process is the generation of clear standard operating protocols, which verify and validate the entire process. Such a process should be straightforward to implement, optimize for efficiency and eliminate all unnecessary or redundant steps. For example, lentiviral vectors may be preferred over gamma retroviral vectors and non-viral methods as they can be simply and directly added to the cell culture vessel (in closed systems) and demonstrate very high transduction efficiency. ${ }^{27}$ Lentiviral vectors have the added advantage that they efficiently transduce non-dividing, as well as dividing cells, and they have low genotoxic potential, in contrast to gamma retroviral vectors. ${ }^{28,29}$

Ideally, the process should become sufficiently robust to yield equivalent product quality independently of the patient-derived cell source material and possibly the T-cell receptor or CAR used to modify the T cells, assuming the transgene does not drastically impact the physiology of the expanding T-cell population.

\section{SIMPLIFYING THE PROCESS: IMPLEMENTING AUTOMATION}

As established in multiple industries, the best way to standardize a complex process is to automate it as much as possible. There are currently on the market a large number of devices that can be used to perform parts of the process (Figure 2). For example, the COBE cell processor (Terumo BCT) can be used for cell processing and washing while maintaining the cells in a closed system. Recently, a number of devices have been designed to simplify and even automate the expansion of the stimulated and genemodified T cells. For example, GE Healthcare (Pittsburgh, PA, USA) has successfully developed their Xuri cell expansion system which allows the expansion of T cells to large numbers (up to $10^{11}$ depending on the model) using bags lying on a rocking platform capable of maintaining the desired temperature. ${ }^{30}$ The bag is connected to a gas control unit capable of running in continuous cultivation mode with cell retention by a filtration device. The system behaves as an independent expansion unit. Another interesting tool that simplifies T-cell expansion is the G-Rex Technology (Wilson Wolf, New Brighton, MN, USA). This device takes advantage of the properties of gas-permeable membranes to culture cells at high cell density in a flask that can be simply placed into an incubator. An advantage of such a device is the possibility to start from low cell densities (less critical-seeding dose required) and expand cells to high cell numbers with reduced feeding needs compared with the Xuri. ${ }^{31,32}$ A pump allows cell feedings without having to 'open' the closed tubing set. This system requires an incubator to maintain proper gas and temperature control. Nevertheless, open steps are part of this process, such as during inoculation of the flask. The current conventional process of manufacturing gene-modified $T$ cells requires several devices: one to isolate and enrich cells, one to wash and concentrate, one to incubate and/or expand the T cells, implementation of transduction procedures, a microscope to view the cells and so on, depending upon the specific procedure. The

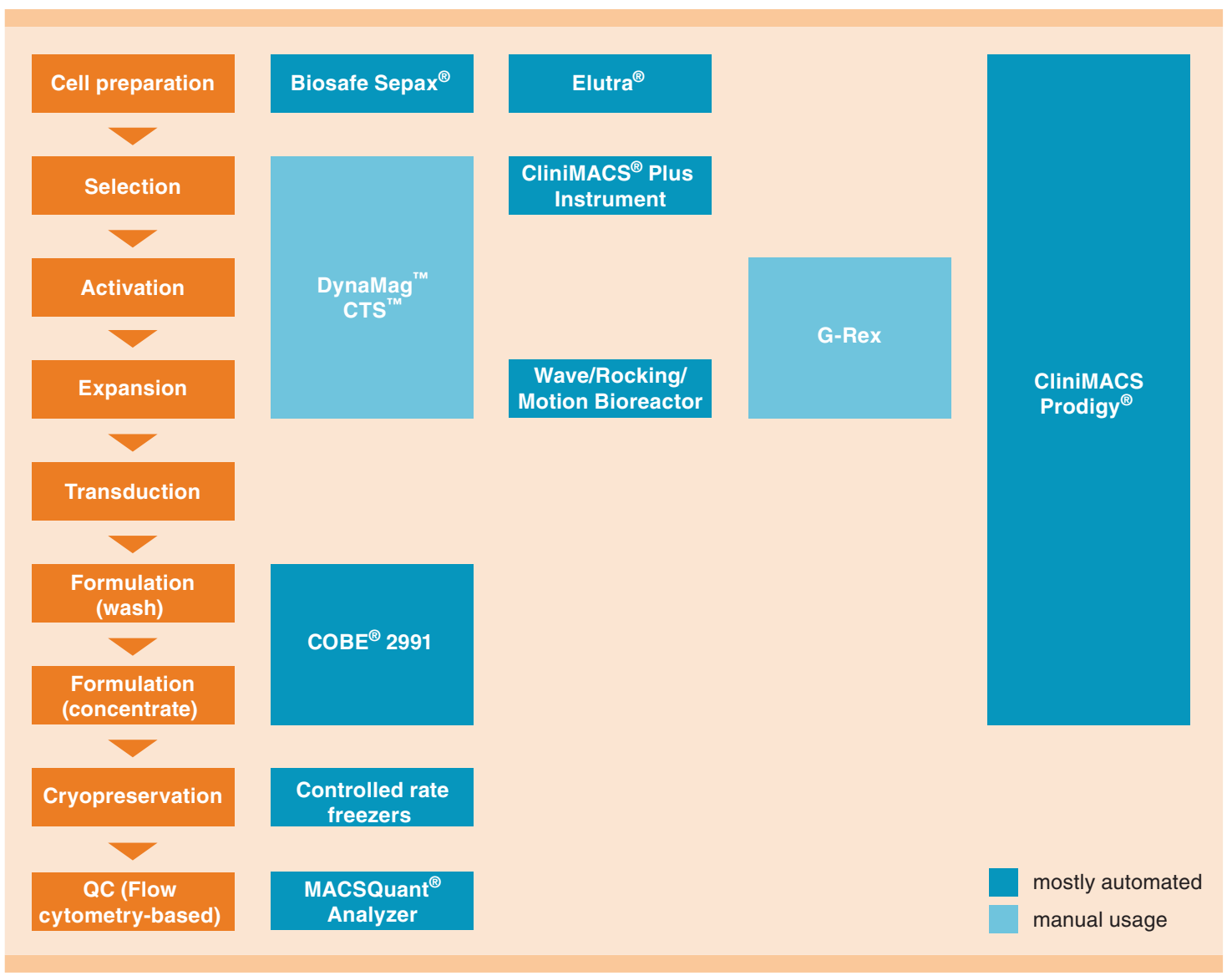

Figure 2. Examples of devices that can facilitate the clinical-grade manufacturing of $\mathrm{T}$ cells. 
use of multiple devices requires significant operator interaction and support. Each device must work seamlessly with the others without interference, personnel must be trained, installation and servicing must be scheduled, operational and performance qualification must be in place before cGMP gene-modified T-cell products can be manufactured.

There is a new device available-The CliniMACS Prodigy (Miltenyi Biotec) - which is capable of performing automatically all these steps: from cell preparation, enrichment, activation, transduction, expansion to final formulation and sampling in a closed sterile, single use tubing set. ${ }^{33}$ Currently it is used in the clinic for the enrichment of stem cells and the preparation of virus-reactive $T$ cells. It is being developed as a platform for integrated and functionally closed manufacturing of engineered T cells with minimal user interaction. This approach will greatly simplify and improve robustness of the manufacturing process whereas freeing available resources for other tasks.

Another challenge for reproducible production of effector T-cell populations which could benefit from further improvement are inprocess control and quality control steps. These are essential in any manufacturing process and should be simplified. Automation can again be of help here, provided the existence of a reliable and safe sampling method. For example, flow cytometric analysis of cultured cell populations would benefit from automated (nowash) staining, acquisition and analysis processes, as is possible with the MAQSQuant Express Mode. Clustering programs, that is automated analysis of flow cytometric data, have become powerful $^{34}$ and may be preferred over standard user based analysis where harmonization is harder to reach as demonstrated by the results of proficiency panel studies. ${ }^{35}$ Automated acquisition and analysis of flow data also presents the possibility to rapidly generate standardized documentation by using LIMS (Laboratory Information and Management System) and significantly reduce workload. Therefore, automated batch recording should be implemented whenever possible and can probably most easily be delivered by a one system/device solution with material tracking, ideally in close connection to corresponding Inprocess control and quality control systems. This needs to be imbedded into a full tracking system for the logistic supply chain from sampling of the starting material to the very end of the process, infusion into a patient.

Keeping track of documentation during the manufacturing process is an obligatory and time-consuming task. The implementation of bar code readers permits rapid in-process batch recording of raw materials used during production and can allow a highly standardized protocol to be automatically generated at the end of each run.

\section{SCALABILITY: TOWARDS COST EFFECTIVE COMMERCIAL SCALE MANUFACTURE}

Organizing the production of a few dozen cellular products a year can be arranged in a straightforward manner, with limited infrastructure and personnel using the above mentioned methods that are currently in place in a number of centers. However, when implementing manufacturing processes for phase II/III clinical trials with the goal of FDA approval, new sets of challenges arise to produce the hundreds or even thousands of cell therapeutic doses per year that are required. The obligation to entirely avoid any cross contamination between patient products requires working in closed systems (e.g., bags and tubing sets), strict physical separation, decontamination of hoods, incubators and so on for each individual cell product, and the controlled and standardized compounding of reagents (controlling supply, storage of perishables, such as cytokines, large volumes of media and so on) and materials (e.g., plastics). To be successful, genemodified T-cell therapy must meet these demands and therefore the manufacturing method used must be standardized and scalable. We present several strategic points to address the problems at hand to advance the field.

\section{The production line}

A solution that can be adapted from other automated industries is the production line, where a specific product moves from one station to the next. With a significant upfront investment to set up and organize the proper infrastructure, such manufacturing methods can be applied to the production of gene-modified $T$ cells. As represented in Figure $3 a$, the patient's cells would enter the 'processing station' where a skilled operator would have the task to document and prepare (e.g., perform washes, density gradient separation, subset isolation) enriched $T$ cells, as well as activate them (i.e., addition of stimulatory reagent). The cells would then move into a (physically) separated space to be transduced (i.e., addition of viral vector). Line clearance protocols have to be followed between the handling of different patients' cell products. Cells could then be placed in an adjacent suite organized to accommodate the expansion of the cells either using individual stations or modular spaces to accommodate the chosen expansion method.

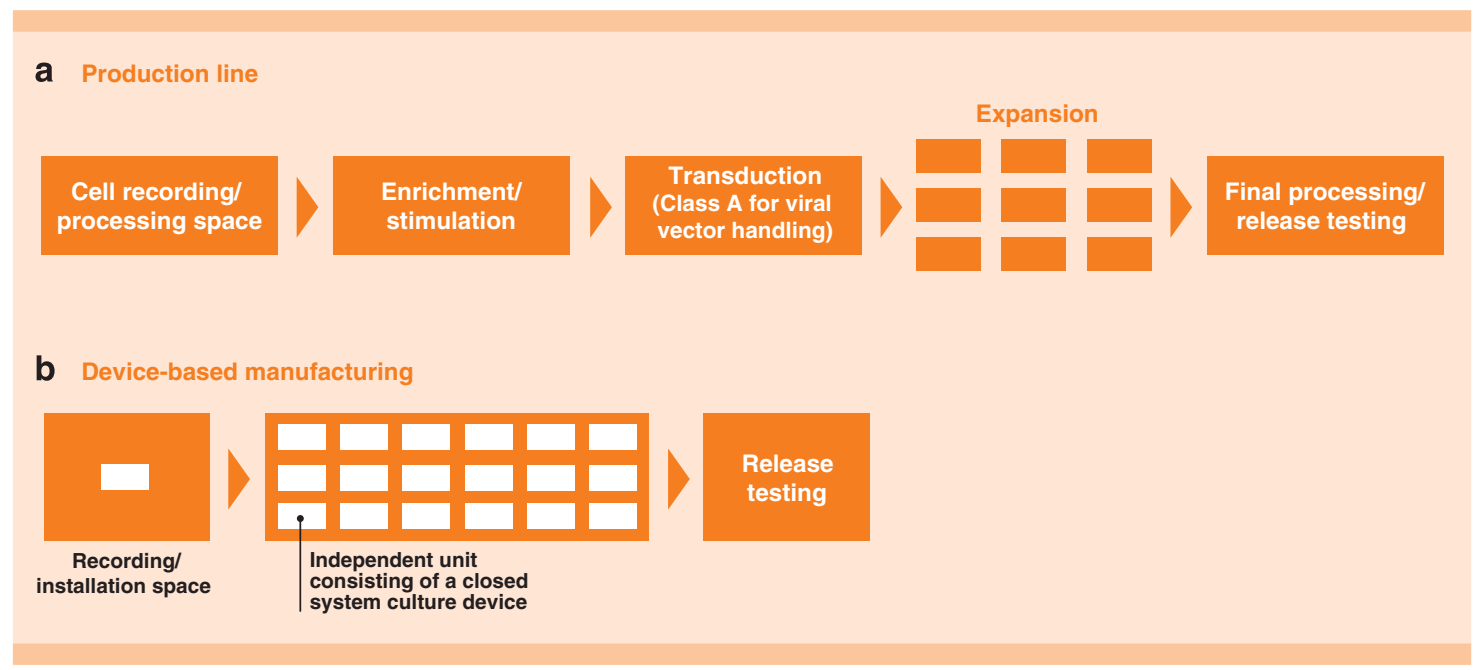

Figure 3. Models of cell manufacturing centers. 
Modular manufacturing platforms are being established by multiple groups. For example, BioSpherix (Lacona, NY, USA) have created the Xvivo modular laminar flow system where cell products can be moved through a series of physically separated spaces, each dedicated for the specific part of the process. Although clearly having several advantages over other approaches, this system still requires a large number of handling steps and therefore highly skilled operators to enable them. Such labor-intensive approaches also gravitate towards a centralized manufacturing model because of the additional difficulty of maintaining the reproducibility of products that are manufactured at multiple sites.

\section{Device-based manufacturing}

Another solution for scalable manufacturing would consist in taking advantage of existing devices dedicated to the clinical manufacturing of cellular products such as the CliniMACS Prodigy. In this case, one device is dedicated to the production of one patient product at a time. This unit-based production would preferentially be organized in more open areas where an operator could oversee several units at the same time (Figure 3b). Such organization assumes that the devices must operate independently, with minimal user interaction and have adequate error handling capacity. In the ideal case there would not only be warning indicators for unplanned events (i.e., low temperature detection, or recovery after electrical failure) but a redundancy of back up procedures. Cross-contamination is prevented by physical delimitation of each working unit. Validated barcode systems ensure identification and control of the material involved in a given manufacturing unit and during QC sampling.

Such device-based manufacturing directly relies on the performance and robustness of the chosen device(s), but it has the advantage of being highly adaptable, for example, one functional area of 4-5 devices could rapidly be changed between two protocols by simply using a different program on the device, whereas maintaining the structural organization in place. Typically, in production lines, defects in one position of the chain can affect the rest of the production line as it is a linear process. In a devicebased manufacturing, dysfunction of a unit does not impact other products and it can be rapidly exchanged by another device where the process can be resumed.

GMP facilities with many separated class $A / B$ room suites may be limited towards commercial efficiency, for example, in a $2000 \mathrm{~m}^{2}$ facility with, for example, 20 such clean rooms, about 500 cellular products per year can be generated (assuming 25 products manufactured by a 10 day process per room per year). In contrast, 200 automated devices could be placed in the same facility and could process about 5000 corresponding cellular products with fewer personal and lower clean room requirements and thereby costs.

\section{Cost-effectiveness}

To be viable, the cell manufacturing process must meet economical requirements for the pharmaceutical manufacturer, the treating clinicians, and for payers, such as health insurance companies that reimburse the therapy. Health-care providers must be able to pharmaco-economically justify the use of a high cost one-time gene-modified T-cell therapy over the available standard of care. This means that reducing the cost whereas maintaining quality will become crucial as the demand for these types of products increases. Therefore robust manufacturing systems with a low failure rate of production will likely prevail as repeat manufacture of these products would be prohibitively costly. In the future, methods to abbreviate costly testing of these products, without compromising safety, will be important to further reduce their overall cost. This will be possible when more experience is gained as to the critical parameters for release testing that ensure product safety.

Costs could be further reduced by incrementally depersonalizing personalized therapy. Currently, the great majority of retargeted T-cell therapies imply preparing a cellular product for each individual patient from their own cells. However, some groups are investigating the possibility to use off-the-shelf third party donor gene-modified $T$ cells for the treatment of viral infections. ${ }^{36}$ Such universal cell therapy could be designed by taking advantage of additional gene modifications such as the knock-down of the human leukocyte antigen genes coupled with enforced expression of non-classical human leukocyte antigen molecules to avoid natural killer cell-mediated lysis ${ }^{37}$ and the knock-down of endogenous T-cell receptors. ${ }^{38}$ Although this approach to cell therapy is likely to be less dependent on improved and scalable manufacturing strategies such as those required for autologous cell therapies, it too will require solutions to generate very large batches of cells while retaining their functionality, which is challenging as $T$ cells tend to be less effective after repeated stimulations. ${ }^{2,39}$ Also, different batches will need to be produced for each new antigenic target being investigated and may require different manufacturing strategies for each. Although universal cell therapy approaches are clearly attractive, their safety and efficacy is yet to be proven, and further research is required before practical plans for manufacture can be initiated.

\section{REGULATORY REQUIREMENTS}

One of the major challenges of bringing personalized cellular products into standard therapy is that the production process is patient specific. Regulatory agencies are very familiar with drug manufacturing, but cellular products have special requirements. Although regulatory authorities are working to define optimal guidelines that can be harmonized, the requirements for clinical manufacturing of ATMP (advanced therapy medicinal products) are becoming clearer. The requirements of ATMP are summarized in the European regulation 1394/2007 where gene therapy medicinal product are now defined (\$2) (REGULATION (EC) No $1394 / 2007$ on advanced therapy medicinal products). In the USA, the requirements can be found in the document entitled 'Guidance for Human Somatic Cell Therapy and Gene Therapy'. ${ }^{40}$

If one patient dose equals one product, this also means each patient's product represents an entire manufacturing batch. Therefore an enormous number of QC-samples must be processed in comparison with conventional medicinal approaches. This increased QC sampling could impact the time necessary to release the product and freezing the cells may become necessary in certain circumstances. To prevent contamination and cross contamination of other cell products, a commercial manufacturing process using closed systems is likely the only option to reduce manufacturing costs by working in clean rooms, class 10000 /ISO 7.

Materials used during ex vivo manipulation procedures; for example antibodies, cytokines, serum, other chemicals, or solid supports such as beads and especially the virus-based gene vectors can affect the safety, purity and potency of the final therapeutic product. These components should be clearly identified and a qualification program with set specifications should be established for each component to determine its acceptability for use during the manufacturing process. ${ }^{40}$

\section{IN-PROCESS CONTROL AND QUALITY CONTROL}

QC tests and release testing are an essential component of the manufacturing of ATMPs. Because of high complexity, cellular products and their testing have demanding requirements for appropriate in-process and quality control. This is dramatically 
increased for individualized compared with universal cell products. Individualized cell products are more restricted in the amount of material available for testing and time for which the cell product is available for testing. Furthermore, actual testing must be performed in a timely manner as these products have a limited shelf-life prior to infusion or cryopreservation. Complexity of certain assays, particularly cellular functional assays, can increase the risk of mistakes and generate unreliable data.

One should clearly distinguish the release criteria, which are essential for clearing the cellular product for patient use, from tests 'for information only' which are more research driven and do not relate to patient safety. It is clear, however, that harmonization of quality control assays and criteria for release will help to define and advance cellular therapy. ${ }^{41}$ Indeed, the possibility of comparing QC data across different manufacturing sites and different processes worldwide will mean improved and more reliable understanding of the cellular product. Here again automated platforms that adhere to established guidelines will be of great help.

\section{MODELS FOR THE COMMERCIAL MANUFACTURE OF GENE- MODIFIED T-CELL PRODUCTS}

As discussed previously there are ongoing attempts to generate 'universal' cellular products. The manufacturing of such products could be similar to other biologics, such as vaccines and monoclonal antibodies, taking place in single industrial scale manufacturing sites, despite the increased complexity of storage of these products and delivery to the patients.

It is debatable whether the same concepts are also suited for individualized personalized autologous cell products. Instead of one product being manufactured at large scale, and then stored and shipped in individual vials, many similar products need to be efficiently produced at small scale, probably many in parallel with non-synchronous overlapping production slots. The method chosen to produce patient-specific ATMPs, that is, production line or device based, will guide the model of commercial manufacturing. When relying on a multitude of devices and operators to run the process, a critical size infrastructure is necessary to find the best balance between costs and production, as well as center location and area coverage for logistics. Appropriate logistics for delivery of the patient-derived starting material to the production facility and back to the patient must cover the harvesting of the starting material at the patient's center-of-care, transport, modification and expansion, then storage and transport back to the patient in a totally transparent and traceable manner. Although shipping companies can provide complete solutions for this task including validated cell-shipping and chain-of-custody procedures, it is important to note that the manufacturer is ultimately responsible and has to address this task carefully to ensure maximum product safety.

An alternative to centralized manufacturing models are localized manufacturing options, at the patients' point-of-care. Achieving a high level of product quality with a decentralized manufacturing model requires highly standardized, robust and transparent manufacturing processes and platforms. Transfer of production know-how for the set up of new production facilities is best achieved with highly automated processes for production and IPC/QC as the device and programs that control the runs are identical. However, for an easy transfer and robust operation across several production sites it is important to ensure availability of the same components and reagents to all sites.

Platforms such as the CliniMACS Prodigy that enable the automated manufacturing of gene-modified T cells from the initial harvest from the patient to the final formulated product are highly exportable. This device-centric approach relies less on infrastructure for the cell processing than production lines and therefore, smaller, more regional facilities can be envisaged. Such regional facilities may now become less difficult to build (smaller, less expensive and with lower needs in terms of cleanroom environment) and could facilitate improved patient scheduling and availability (for sourcing of patient cells and infusion of final product) with local care providers.

The decentralized manufacturing model applies only for the final steps in the manufacturing process-gene modification of the patients' cells. The manufacture of all non-patient specific components, such as ancillary reagents, viral vectors and so on, will mostly remain centralized as it is closer to a pharmaceutical manufacturing model where one batch is used for many cell product applications.

It is conceivable to see a future where gene-modified T cells are manufactured at the point-of-care in a facility in close proximity, associated with, or at the hospital. This will depend on the robustness of patient-specific automated T-cell manufacturing and how the regulatory authorities will ultimately regulate the manufacturing and use of gene-modified T cells. Nevertheless, such a decentralized mode for delivering cell-based drug products to patients will certainly decrease the risks to the product and costs, particularly the to-and-fro transportation that are associated with centralized manufacturing facilities. In addition to the increased risk to product integrity and cost, transportation may also compromise the quality of the cell product by necessitating, for example, its freezing for shipping. This would not be the case with local decentralized facilities. Decentralized facilities located in hospitals would reduce these risks and also incentivize hospitals to adopt such long-lasting cellular therapies as they would then become a significant part of the value chain. Such a model near the point-ofcare, where the manufacturing and QC methods are safe and reliable to operate, would be the preferred option for bringing personalized cell therapy to patients with high medical need.

\section{CONFLICT OF INTEREST}

ADK, MA, BS, MM and UB are employees of Miltenyi Biotec $\mathrm{GmbH}$. RO and BD are employees of Lentigen Technology Inc.

\section{REFERENCES}

1 Anurathapan U, Leen AM, Brenner MK, Vera JF. Engineered T cells for cancer treatment. Cytotherapy 2014; 16: 713-733.

2 Kalos M. Biomarkers in T cell therapy clinical trials. J Transl Medicine 2011; 9: 138. 3 Maus MV, Fraietta JA, Levine BL, Kalos M, Zhao Y, June CH. Adoptive immunotherapy for cancer or viruses. Ann Rev Immunol 2014; 32: 189-225.

4 Park TS, Rosenberg SA, Morgan RA. Treating cancer with genetically engineered T cells. Trends Biotechnol 2011; 29: 550-557.

5 Kalos M, Levine BL, Porter DL, Katz S, Grupp SA, Bagg A et al. T cells with chimeric antigen receptors have potent antitumor effects and can establish memory in patients with advanced leukemia. Sci Transl Med 2011; 3: 95ra73.

6 Maus MV, Grupp SA, Porter DL, June CH. Antibody-modified T cells: CARs take the front seat for hematologic malignancies. Blood 2014; 123: 2625-2635.

7 Lee DW, Barrett DM, Mackall C, Orentas R, Grupp SA. The future is now: chimeric antigen receptors as new targeted therapies for childhood cancer. Clin Cancer Res 2012; 18: 2780-2790.

8 Brenner MK. Will T-cell therapy for cancer ever be a standard of care? Cancer Gene Ther 2012; 19: 818-821.

9 Tumaini B, Lee DW, Lin T, Castiello L, Stroncek DF, Mackall C et al. Simplified process for the production of anti-CD19-CAR-engineered T cells. Cytotherapy 2013; 15: 1406-1415.

10 Bellone G, Turletti A, Artusio E, Mareschi K, Carbone A, Tibaudi D et al. Tumorassociated transforming growth factor-beta and interleukin-10 contribute to a systemic Th2 immune phenotype in pancreatic carcinoma patients. Am J Pathol 1999; 155: 537-547.

11 Decker T, Fischer G, Bucke W, Bucke P, Stotz F, Gruneberger A et al. Increased number of regulatory $T$ cells (T-regs) in the peripheral blood of patients with Her2/neu-positive early breast cancer. J Cancer Res Clin Oncol 2012; 138: 1945-1950.

12 Karp JE, Ricklis RM, Balakrishnan K, Briel J, Greer J, Gore SD et al. A phase 1 clinicallaboratory study of clofarabine followed by cyclophosphamide for adults with refractory acute leukemias. Blood 2007; 110: 1762-1769. 
13 Goldstein MJ, Kohrt HE, Houot R, Varghese B, Lin JT, Swanson E et al. Adoptive cell therapy for lymphoma with CD4 T cells depleted of CD137-expressing regulatory T cells. Cancer Res 2012; 72: 1239-1247.

14 Gomez-Eerland R, Nuijen B, Heemskerk B, van Rooij N, van den Berg JH, Beijnen $\mathrm{JH}$ et al. Manufacture of Gene-Modified Human T Cells with a Memory Stem/ Central Memory Phenotype. Human Gene Ther Methods 2014; 25: 277-287.

15 Porter DL, Levine BL, Bunin N, Stadtmauer EA, Luger SM, Goldstein S et al. A phase 1 trial of donor lymphocyte infusions expanded and activated ex vivo via CD3/ CD28 costimulation. Blood 2006; 107: 1325-1331.

16 van Loenen MM, de Boer R, van Liempt E, Meij P, Jedema I, Falkenburg JH et al. A good manufacturing practice procedure to engineer donor virus-specific $T$ cells into potent anti-leukemic effector cells. Haematologica 2014; 99: 759-768.

17 Louis CU, Savoldo B, Dotti G, Pule M, Yvon E, Myers GD et al. Antitumor activity and long-term fate of chimeric antigen receptor-positive $T$ cells in patients with neuroblastoma. Blood 2011; 118: 6050-6056.

18 Pule MA, Savoldo B, Myers GD, Rossig C, Russell HV, Dotti G et al. Virus-specific $T$ cells engineered to coexpress tumor-specific receptors: persistence and antitumor activity in individuals with neuroblastoma. Nat Med 2008; 14: 1264-1270.

19 Berger C, Jensen MC, Lansdorp PM, Gough M, Elliott C, Riddell SR. Adoptive transfer of effector CD8+ T cells derived from central memory cells establishes persistent T cell memory in primates. J Clin Investig 2008; 118: 294-305.

20 Gattinoni L, Lugli E, Ji Y, Pos Z, Paulos CM, Quigley MF et al. A human memory T cell subset with stem cell-like properties. Nat Med 2011; 17: 1290-1297.

21 Hinrichs CS, Borman ZA, Gattinoni L, Yu Z, Burns WR, Huang J et al. Human effector CD8+ $T$ cells derived from naive rather than memory subsets possess superior traits for adoptive immunotherapy. Blood 2011; 117: 808-814.

22 Klebanoff CA, Gattinoni L, Restifo NP. Sorting through subsets: which T-cell populations mediate highly effective adoptive immunotherapy? I Immunother 2012; 35: 651-660.

$23 \mathrm{Xu} \mathrm{Y,} \mathrm{Zhang} \mathrm{M,} \mathrm{Ramos} \mathrm{CA,} \mathrm{Durett} \mathrm{A,} \mathrm{Liu} \mathrm{E,} \mathrm{Dakhova} \mathrm{O} \mathrm{et} \mathrm{al.} \mathrm{Closely} \mathrm{related}$ T-memory stem cells correlate with in vivo expansion of CAR.CD19-T cells and are preserved by IL-7 and IL-15. Blood 2014; 123: 3750-3759.

24 Casati A, Varghaei-Nahvi A, Feldman SA, Assenmacher M, Rosenberg SA, Dudley $\mathrm{ME}$ et al. Clinical-scale selection and viral transduction of human naive and central memory CD8+ T cells for adoptive cell therapy of cancer patients. Cancer Immunol Immunother 2013; 62: 1563-1573.

25 Terakura S, Yamamoto TN, Gardner RA, Turtle CJ, Jensen MC, Riddell SR. Generation of CD19-chimeric antigen receptor modified CD8+ $T$ cells derived from virus-specific central memory T cells. Blood 2012; 119: 72-82.

26 Brindley DA, Davie NL, Culme-Seymour EJ, Mason C, Smith DW, Rowley JA. Peak serum: implications of serum supply for cell therapy manufacturing. Regen Med 2012; 7: 7-13.

27 Dropulic B. Lentiviral vectors: their molecular design, safety, and use in laboratory and preclinical research. Human Gene Ther 2011; 22: 649-657.

28 Biffi A, Bartolomae CC, Cesana D, Cartier N, Aubourg P, Ranzani M et al. Lentiviral vector common integration sites in preclinical models and a clinical trial reflect a benign integration bias and not oncogenic selection. Blood 2011; 117: 5332-5339.

29 Wang GP, Levine BL, Binder GK, Berry CC, Malani N, McGarrity G et al. Analysis of lentiviral vector integration in HIV+ study subjects receiving autologous infusions of gene modified CD4+ T cells. Mol Ther 2009; 17: 844-850.
30 Somerville RP, Devillier L, Parkhurst MR, Rosenberg SA, Dudley ME. Clinical scale rapid expansion of lymphocytes for adoptive cell transfer therapy in the WAVE(R) bioreactor. J Transl Med 2012; 10: 69.

31 Jin J, Sabatino M, Somerville R, Wilson JR, Dudley ME, Stroncek DF et al. Simplified method of the growth of human tumor infiltrating lymphocytes in gas permeable flasks to numbers needed for patient treatment. J Immunother 2012; 35: 283-292.

32 Bajgain P, Mucharla R, Wilson J, Welch D, Anurathapan U, Liang B et al. Optimizing the production of suspension cells using the G-Rex ' $M$ ' series. Mol Ther 2014; 1.

33 Apel M, Brüning M, Granzin M, Essl M, Stuth J, Blaschke J et al. Integrated clinical scale manufacturing system for cellular products derived by magnetic cell separation, centrifugation and cell culture. Chemie Ingenieur Technik 2013; 85: 103-110.

34 Aghaeepour N, Finak G, Hoos H, Mosmann TR et al. FlowCAP Consortium, DREAM Consortium Critical assessment of automated flow cytometry data analysis techniques. Nat Methods 2013; 10: 228-238.

35 McNeil LK, Price L, Britten CM, Jaimes M, Maecker H, Odunsi K et al. A harmonized approach to intracellular cytokine staining gating: Results from an internationa multiconsortia proficiency panel conducted by the Cancer Immunotherapy Consortium (CIC/CRI). Cytometry A 2013; 83: 728-738.

36 Leen AM, Bollard CM, Mendizabal AM, Shpall EJ, Szabolcs P, Antin JH et al. Multicenter study of banked third-party virus-specific T cells to treat severe viral infections after hematopoietic stem cell transplantation. Blood 2013; 121: 5113-5123.

37 Torikai H, Reik A, Soldner F, Warren EH, Yuen C, Zhou Y et al. Toward eliminating HLA class I expression to generate universal cells from allogeneic donors. Blood 2013; 122: 1341-1349.

38 Torikai H, Reik A, Liu PQ, Zhou Y, Zhang L, Maiti S et al. A foundation for universal T-cell based immunotherapy: T cells engineered to express a CD19-specific chimeric-antigen-receptor and eliminate expression of endogenous TCR. Blood 2012; 119: 5697-5705.

39 Gattinoni L, Klebanoff CA, Palmer DC, Wrzesinski C, Kerstann K, Yu Z et al. Acquisition of full effector function in vitro paradoxically impairs the in vivo antitumor efficacy of adoptively transferred CD8+ T cells. J Clin Investig 2005; 115: $1616-1626$.

40 Guidance for industryfda guidance for human somatic cell therapy and gene therapy. 1998.

41 van der Burg SH, Kalos M, Gouttefangeas C, Janetzki S, Ottensmeier C, Welters MJ et al. Harmonization of immune biomarker assays for clinical studies. Sci Transl Med 2011; 3: 108ps44.

This work is licensed under a Creative Commons Attributioncc) NonCommercial-ShareAlike 4.0 International License. The images or other third party material in this article are included in the article's Creative Commons license, unless indicated otherwise in the credit line; if the material is not included under the Creative Commons license, users will need to obtain permission from the license holder to reproduce the material. To view a copy of this license, visit http:// creativecommons.org/licenses/by-nc-sa/4.0/ 